\title{
PERAN KEPEMIMPINAN DALAM KINERJA ORGANISASI MELALUI SISTEM AKUNTANSI MANAJEMEN DAN SISTEM PENGENDALIAN MANAJEMEN
}

\author{
Jeni Wardi \\ Program Doktor Ilmu Manajemen \\ Universitas Persada Indonesia Y.A.I \\ E-mail : wardi_jeni@yahoo.com
}

\begin{abstract}
This study aims to study the direct influence of transformational and transactional leadership styles on organizational performance. This study also aims to study the effect of transformational and transactional leadership styles on organizational performance through organizational management accounting systems and management control systems. In addition, another purpose of this study is to study the direct effects of the organization's management accounting system and management control systems on organizational performance. This research involves descriptive design and inference in problem solving research. To test the model and hypothesis used SEM analysis. The population of this study are all companies listed in Indonesia Stock Exchange period 2012, with sample selection technique using purposive sampling technique. Research data were also taken using questionnaires distributed to respondents. The respondents of this study are corporate managers who are represented by accounting managers and financial managers with positions 1 and 2 under the top management team who have direct communication with top management. The results showed that the transformational leadership style proved to significantly influence the management accounting system management control system and organizational performance. Transactional leadership style proved significantly influence on management accounting system and organizational performance, while the performance of the organization did not significantly influence. Management control system proved to have a significant effect on organizational performance. Management accounting system proved to have no significant effect on organizational performance. The dominant variable is the transformational leadership style.
\end{abstract}

Keywords: Leadership Style, Transformational, Transactional, Management Accounting System, Management Control System, Organizational Performance

\section{PENDAHULUAN}

Sumber daya manusia merupakan aset terpenting perusahaan karena perannya sebagai subjek pelaksana kebijakan dan kegiatan operasional perusahaan. Agar perusahaan tetap eksis maka harus berani menghadapi tantangan dan implikasinya yaitu menghadapi perubahan dan memenangkan persaingan. Sumber daya yang dimiliki oleh perusahaan seperti modal, metode, dan mesin tidak bisa memberikan hasil yang optimum apabila tidak didukung oleh sumber daya manusia yang mempunyai kinerja yang optimum. Bagian penting dalam permasalahan sumber daya manusia yang berkaitan dengan kinerja perusahaan adalah masalah kepemimpinan dan kinerja karyawan.

Sebagaimana diketahui bahwa salah satu cara melihat kinerja perusahaan secara komprehensif adalah melalui pengukuran CGPI (Corporate Gocernance Perception Index). CGPI sendiri dalam hal ini merupakan pemeringkatan penerapan Good Corporate Governance (GCG) pada perusahaan-perusahaan di Indonesia melalui riset yang dirancang untuk mendorong perusahaan meningkatkan kualitas penerapan konsep Corporate 
Governance (CG) melalui perbaikan yang berkesinambungan (continuous improvement) dengan melaksanakan evaluasi dan melakukan patok banding (benchmarking) (The Indonesian Institute for Corporate Governance, 2012: 2). Pada kenyataannya, tidak jarang kinerja suatu organisasi perusahaan mengalami peningkatan atau penurunan dari waktu ke waktu. Hal demikian dapat terjadi karena pengukuran kinerja melalui CGPI dilakukan terhadap beberapa aspek sebagai kriterianya. Oleh sebab itu, skor CGPI organisasi perusahaan yang tidak stabil menunjukan bahwa kondisi aspekaspek yang diukur guna menentukan skor kinerja organisasi perusahaan juga mengalami dinamika di dalamnya.

Penelitian ini berbeda dengan penelitian dalam literatur akuntansi sebelumnya karena melibatkan perspektif yang luas di luar disiplin ilmu akuntansi, yaitu: (1) kepemimpinan, budaya organisasi, manajemen strategi, dan sistem pengendalian manajemen; (2) menggunakan pendekatan integratif untuk variabel kepemimpinan dan budaya organisasi.

\section{TINJAUAN PUSTAKA}

Pada penelitian ini, induk teori (grand theory) yang digunakan adalah teori kontinjensi. Teori kontinjensi (contingency theory) menyatakan bahwa keselarasan antara strategi dengan lingkungan bisnis eksternal menentukan kelangsungan hidup dan kinerja perusahaan (Child, 1997; Lee \& Miller, 1996). Teori tersebut juga bermakna bahwa tuntutan dari ingkungan eksternal harus dapat diakomodasi dalam perencanaan strategi (Elenkov, 1997). Hal demikian dikarenakan menurut pandangan teori kontinjensi apabila tidak tercipta keselarasan antara lingkungan eksternal dan perencanaan strategi maka suatu organisasi atau perusahaan dapat mengalami krisis akibat terjadinya penurunan kinerja (Elenkov, 1997).

Pada penelitian ini, teori antara (midle range theory) yang digunakan adalah teori kinerja organisasi. Kinerja organisasi dalam hal ini dapat dipahami dari definisi istilah kinerja itu sendiri. Mangkunegara (2006) menyatakan kinerja dapat didefinisikan sebagai hasil kerja secara kualitas dan kuantitas yang dapat dicapai oleh seseorang pegawai dalam melaksanakan tugas sesuai dengan tanggungjawab yang diberikan kepadanya. Sementara itu, Simamora (2001) mengartikan kinerja sebagai tingkat peran karyawan mencapai persyaratan-persyaratan pekerjaan, sedangkan Dharma (2002) mendefinisikan kinerja sebagai sesuatu yang dikerjakan, produk, ataupun jasa yang dihasilkan seseorang atau sekelompok orang. Berdasarkan uraian tersebut, dapat dilihat bahwa kinerja organisasi dalam hal ini memuat dua aspek, yaitu dari sisi individu-individu dalam organisasi maupun capaian dari organisasi itu sendiri.

Pada penelitian ini, teori terapan (application theory) yang digunakan adalah teori kepemimpinan. Pada dasarnya, kepemimpinan adalah tindakantindakan seseorang atau beberapa orang yang mempengaruhi kelakuan orang lain atau beberapa orang dalam suatu kerangka kelompok (Wirjana dan Supardo, 2005: 20). Masalah kepemimpinan telah muncul bersamaan dengan dimulainya sejarah manusia, yaitu sejak manusia menyadari pentingnya hidup berkelompok untuk mencapai tujuan bersama. Mereka membutuhkan seseorang atau beberapa orang yang mempunyai kelebihankelebihan daripada yang lain, terlepas dalam bentuk apa kelompok manusia itu dibentuk. Hal ini tidak dapat dipungkiri karena manusia selalu mempunyai keterbatasan dan kelebihan-kelebihan 
tertentu. Menurut Yuki (2005), kepemimpinan adalah proses untuk mempengaruhi orang lain, untuk memahami dan setuju dengan apa yang perlu dilakukan dan bagaimana tugas itu dilakukan secara efektif, serta proses untuk memfasilitasi upaya individu dan kolektif untuk mencapai tujuan bersama. Sementara menurut Robbins (1996), kepemimpinan merupakan kemampuan untuk mempengaruhi suatu kelompok ke arah tercapainya suatu tujuan. Pengertian tersebut menunjukan bahwa aspek untuk dapat mempengaruhi orang lain merupakan aspek penting dalam kepemimpinan.

Lingkungan usaha yang selalu berubah membutuhkan pemimpin yang berfungsi sebagai katalisator perubahan daripada manajer yang menjalankan fungsi administrator, kontrol, dan inisiator (Kreitner dan Kinicki, 2004). Pemimpin sebagai katalisator perubahan bertanggungjawab mempersiapkan dan memimpin organisasi melewati berbagai perubahan dalam hal struktur, strategi, dan budaya organisasi (Weese, 1995). Artinya, peran pemimpin untuk untuk membawa suatu organisasi menuju ke arah pencapaian tujuan merupakan peran yang sangat penting sebab dalam suatu organisasi terdapat berbagai situasi ketidakpastian yang harus dihadapi.

Penelitian ini menggunakan teori kontinjensi dan struktural equation model. Melalui penggunaan teori tersebut akan dapat ditunjukan variabel apa yang berpengaruh terhadap variabel lainnya dan memeriksa hubungan langsung dan bertahap antara variabel sebagai satu kesatuan (tidak seperti regresi berganda yang pendekatannya piecemeal) serta dapat memberikan arah pemodelan mengenai kesesuaian (fitness) hubungan kepemimpinan, budaya, strategi, sistem akuntansi manajemen, dan sistem pengendalian manajemen dengan kinerja perusahaan.

\section{METODE PENELITIAN}

Penelitian ini melibatkan desain deskriptif dan inferensi dalam pemecahan masalah penelitian. Populasi dari penelitian ini adalah seluruh perusahaan yang terdaftar di Bursa Efek Indonesia periode 2012, baik dari lembaga keuangan maupun perusahaan yang bukan lembaga keuangan. Sampel penelitian merupakan sebagian dari anggota populasi yang dipilih berdasarkan teknik tertentu. Penelitian ini menggunakan teknik sampling yaitu purposive sampling.

Metode pengambilan sampel yang dilakukan dalam penelitian ini adalah teknik purposive sampling dikarenakan pemilihan sampel yang dilakukan berdasarkan tujuan dari penelitian dan pertimbangan-pertimbangan tertentu. Populasi yang akan diamati dalam penelitian ini adalah perusahaanperusahaan yang terdaftar di Bursa Efek Indonesia pada tahun 2012 dengan ketentuan-ketentuan sebagai berikut: Sampel yang dipilih memiliki usia listing 5 tahun dan memiliki data tahunan yang lengkap untuk tahun tahun 2012.Bukan lembaga keuangan, perbankan maupun perusahaan pemerintah. Tidak memiliki laba atau total ekuitas negatif pada tahun 2012. Sampel masih tercatat di Bursa Efek Indonesia dan aktif diperdagangkan hingga saat ini.

Data penelitian juga diambil menggunakan kuesioner yang disebar kepada responden. Para responden dari penelitian ini adalah para manajer perusahaan yang diwakili oleh manajer akuntansi dan manajer keuangan dengan posisi 1 dan 2 level di bawah tim manajemen puncak yang memiliki komunikasi secara langsung dengan manajemen puncak.

Penelitian ini dilakukan dengan menggunakan data primer yang dikumpulkan melalui metode survei dengan cara sebagian besar kuesioner dikirimkan melalui pos, faximile, email, 
atau diberikan secara langsung. Kuesioner pada penelitian ini terdiri atas pertanyaan tertutup dan optional. Beberapa pertanyaan kuesioner menggunakan pertanyaan reverse (R) dengan tujuan melihat konsistensi jawaban yang diberikan. Selain kuesioner, data primer dikumpulkan melalui data sekunder yang berupa laporan keuangan perusahaan untuk menambah informasi dalam mendiskripsikan penjelasan tujuan penelitian.

Pengujian hipotesis penelitian diuji menggunaan teknik analisis persamaan model struktural. Structural Equation Modeling (SEM) adalah sekumpulan teknik-teknik statistik yang memungkinkan pengujian sebuah rangkaian hubungan yang relatif "rumit" secara simultan, yaitu rangkaian hubungan yang dibangun antara satu atau beberapa variabel dependen dengan satu atau beberapa variabel independen dimana setiap variabel dependen dan independen berbentuk faktor yang dibangun dari beberapa indikator yang diobservasi atau diukur langsung. SEM dapat dikatakan sebagai kombinasi antara analisis faktor dan analisis regresi berganda.

Analisis model SEM berkembang dan mempunyai fungsi mirip dengan regresi berganda, beberapa variabel bebas laten (multiple latent independents) dimana masing-masing diukur dengan menggunakan banyak indikator, dan satu atau dua variabel tergantung laten yang juga masingmasing diukur dengan beberapa indikator.

\section{HASIL DAN PEMBAHASAN}

Berdasarkan hasil penelitian yang dapat diuraikan sebagai berikut: Gaya kepemimpinan transformasional terbukti berpengaruh secara signifikan terhadap sistem akuntansi manajemen. Hal ini ditunjukkan dengan nilai $\mathrm{t}$ value untuk variabel gaya kepemimpinan transformasional terhadap sistem akuntansi manajemen sebesar 7, Gaya kepemimpinan transformasional terbukti berpengaruh secara signifikan terhadap sistem pengendalian manajemen. Hal ini ditunjukkan dengan nilai $\mathrm{t}$ value untuk variabel gaya kepemimpinan transformasional terhadap sistem pengendalian manajemen sebesar 5,059>1,96. Gaya kepemimpinan transaksional terbukti berpengaruh secara signifikan terhadap sistem akuntansi manajemen. Hal ini ditunjukkan dengan nilai $t$ value untuk variabel gaya kepemimpinan transaksional terhadap sistem akuntansi manajemen sebesar 2,068>1,96 Gaya kepemimpinan transaksional terbukti tidak berpengaruh secara signifikan terhadap sistem pengendalian manajemen. Hal ini ditunjukkan dengan nilai $\mathrm{t}$ value untuk variabel gaya kepemimpinan transaksional terhadap sistem pengendalian manajemen sebesar $1,678<1,96$ Gaya kepemimpinan transformasional terbukti berpengaruh secara signifikan terhadap kinerja organisasi. Hal ini ditunjukkan dengan nilai $t$ value untuk variabel gaya kepemimpinan transformasional terhadap kinerja organisasi sebesar 5,137>1,96 Gaya kepemimpinan transaksional terbukti berpengaruh secara signifikan terhadap kinerja organisasi. Hal ini ditunjukkan dengan nilai $\mathrm{t}$ value untuk variabel gaya kepemimpinan transaksional terhadap kinerja organisasi sebesar 2,861>1,96 Sistem akuntansi manajemen terbukti tidak berpengaruh secara signifikan terhadap kinerja organisasi. Hal ini ditunjukkan dengan nilai $\mathrm{t}$ value untuk variabel sistem akuntansi manajemen terhadap kinerja organisasi sebesar $-1,094<1,96$ Sistem pengendalian manajemen terbukti berpengaruh secara signifikan terhadap 
kinerja organisasi. Hal ini ditunjukkan dengan nilai $t$ value untuk variabel sistem pengendalian manajemen terhadap kinerja organisasi sebesar 5,790>1,96 Gaya kepemimpinan transformasional, transaksional, sistem akuntansi manajemen dan sistem pengendalian manajemen terbukti berpengaruh terhadap kinerja organisasi. Hal ini ditunjukkan dengan nilai $F$ hitung untuk variabel gaya kepemimpinan transformasional, sistem akuntansi manajemen dan sistem pengendalian manajemen terhadap kinerja organisasi sebesar 57,746>2,21 (Tabel 5.1, h.14). Variabel dominan gaya kepemimpinan transformasional.

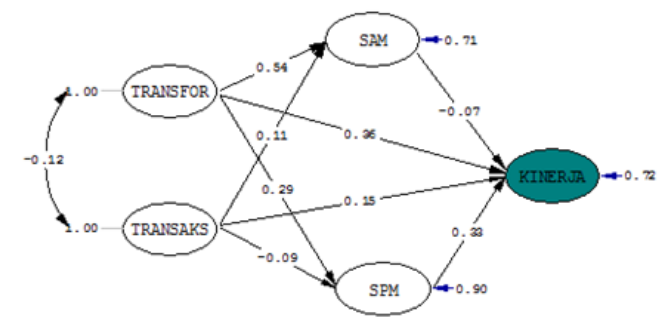

Gambar 1 Model Hybrid SEM (standardized)

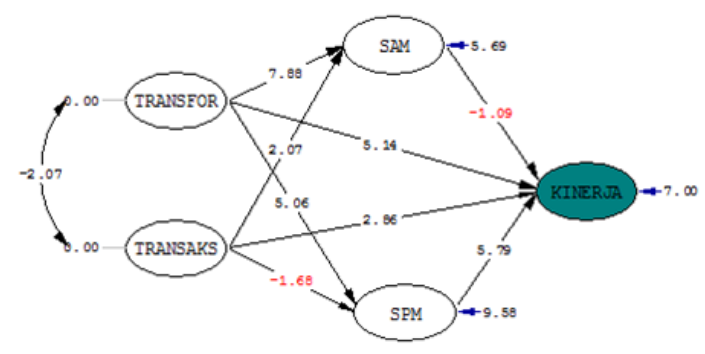

Gambar 2 Model Hybrid SEM (t-value)

\section{KESIMPULAN DAN SARAN}

Berdasarkan hasil penelitian menunjukkan bahwa Gaya kepemimpinan transformasional terbukti berpengaruh secara signifikan terhadap sistem akuntansi manajemen sistem pengendalian manajemen dan kinerja organisasi. Gaya kepemimpinan transaksional terbukti berpengaruh secara signifikan terhadap sistem akuntansi manajemen dan kinerja organisasi, sedangkan terhadap kinerja organisasi tidak berpengaruh secara signifikan. Sistem pengendalian manajemen terbukti berpengaruh secara signifikan terhadap kinerja organisasi. Sistem akuntansi manajemen terbukti tidak berpengaruh secara signifikan terhadap kinerja organisasi. Variabel dominan adalah gaya kepemimpinan transformasional.

Saran manajerial yang dapat direkomendasikan terkait dengan hasil penelitian ini adalah sebagai berikut: Hasil uji hipótesis penelitian membuktikan bahwa pengaruh gaya kepemimpinan transaksional terhadap sistem akuntansi manajemen adalah pengaruh yang paling kecil. Oleh sebab itu, diperlukan upaya untuk meningkatkannya sehingga dapat berpengaruh lebih besar terhadap sistem akuntansi manajemen, sehingga sistem yang diterapkan dapat lebih efektif lagi. Hasil uji hipotesis penelitian membuktikan bahwa pengaruh gaya kepemimpinan transformasional adalah yang memiliki pengaruh dibanding dengan kepemimpinan transaksional terhadap sistem pengendalian manajemen. Oleh sebab itu, perusahaan dapat menggunakan balanced scorecard dalam sistem pengendalian manajemen, karena balanced scorecard tidak hanya mengukur kinerja organisasi dari sisi keuangannya, namun dapat pula mengukur kinerja organisasi non keuangan, sehingga secara keseluruhan kinerja organisasi dapat diketahui. Hasil uji hipotesis penelitian membuktikan bahwa pengaruh langsung gaya kepemimpinan transaksional terhadap kinerja organisasi adalah pengaruh yang paling kecil. Terkait dengan hal tersebut, maka diperlukan upaya untuk meningkatkan pengaruh gaya kepemimpinan transaksional terhadap kinerja. 


\section{DAFTAR PUSTAKA}

Aaker, D., (2003), Manajemen Ekuitas Merek, Alih Bahasa: Aris Ananda, Jakarta: Mitra Utama.

Abdullah dan Herlin Arisanti. 2010. Pengaruh Budaya Organisasi, Komitmen Organisasi dan Akuntanbilitas Publik terhadap Kinerja Organisasi pada Kantor Wilayah Direktorat Jenderal Perbendaharaan Bengkulu. Jurnal Ekonomi dan Bisnis Fakultas Ekonomi Universitas Syiah Kuala Banda Aceh, Volume 9 Nomor 2, Agustus 2010.

Akram, M., H. M. Alam, L. Ali, dan M. M. Mughal, (2012), "How Leadership Behaviors Affect Organizational Performance in Pakistan," Journal of Economics and Behavioral Studies, Vol. 4 (6), 354-363.

Anthony, R. N., (1966), Management Planning dan Control Systems: a Framework for Analysis, Boston: Harvard Business School Press.

Anthony, R., J. Dearden, dan N.M. Bedford, (1989), Management Control Systems, Homewood, III: Irwin.

Anthony, R.N., dan G. Drajan, (2005), Sistem Pengendalian Manajemen, Terjemahan: $\mathrm{K}$. Tjakrawala, Jakarta: Salemba Empat.

Armesh, H., H. Salarzehi, dan B. Kord., (2010), "Management Control System", Interdisciplinary journal of Contemporary
Research in Business, Vol 2 (6), 193-206.

Atkinson, S., dan P. W. Wilson, (1995), "Comparing Mean Efficiency and Productivity Scores From Small Samples: a Bootstrap Methodology", Journal Productivity Anal. 6, 137-152.

Barney, J. B., (1986), “Organizational Culture: Can It Be a Source of Sustained Competitive Advantage?", Academy of Management Review, Vol. 11 (3), 656-665.

Bass, B. M., (1985), Leadership and Performance, New York: Free Press.

Bass, B. M., et.al., (2003), "Predicting Unit Performance by Assessing Transformational and Transactional Leadership". Journal of Applied Psychology, 88 (2), 207-218.

Bass, M.B., dan B.J. Avolio, (1993), "Transformational Leadership and Organizational Culture", Journal PAQ Spring, Binghamton. SUNY.

Bastian, I,, (2001), Akuntansi Sektor Publik. Yogyakarta: Penerbit BPFE, Universitas Gajah Mada.

Beal, R. M., (2000), "Competing Effectively: Environmental Scanning, Competitive Strategy, and Organizational Performance in Small Manufacturing Firms", Journal of Small Business Management, January, 22-45.

Bonner, S. E., dan G.B. Sprinkle, (2002), "The Effects of Monetary Incentives on Effort and Task 
Jurnal Ilmiah Ekonomi dan Bísnis

Vol. 15. No.1, Maret 2018: 42-49

EISSN : $2442-9813$

ISSN : $1829-9822$

Performance: Theories, Evidence, and a Framework for Research", Accounting, Organizations and Society, Vol. 27 (4/5), 303-345.

Buono, A.F., J.L. Bowditch, dan J.W. Lewis, (1985), "When Cultures Collide: The Anatomy of a Merger", Human Relations, Vol. 38 (5), 477-500.

Cadez, S., dan C. Guilding, (2008), “An Explanatory Investigation of An Integrated Contingency Model of Strategic Management Accounting", Accounting, Organization and Society, Vol. 33 (4), 836-863.

Chenhall, R. H., (2007), "Theorising Contingencies in Management Control System Research", In Handbook of Management Accounting Research, United Kingdom: Elsevier, 163-205.

Chenhall, R.H., dan L.K. Smith, (1998), "The Relationship between Strategic Priorities, Management Technique and Management Accounting in the Development of Performance Measures within Organisational

Change Programs", Management Accounting Research, 9, 361386.

Child, J., (1997), "Strategic Choice in the Analysis of Ation, Structure, Organization, and Environtment: Reprospect and Prospect", Orgabizational Studies, Vol. 18, 43-76.

Chow, Y. K., K.S. Merchant, M.D. Shields, dan A. Wu, (1999), "The Importance of National Culture in the Design of and Preference for Management Controls for MultiNatonal Operations", Accounting Organizations and Society, 24: 441-461.

Davila, A., dan G. Foster, (2005), "Startup Firms' Growth, Management Control Systems Adoption and Performance", Working Paper, No. 603, July 2005, Madrid: IESE Business School. University of Navarra.

Davis, K., (1984). "The Case For and Against Business Assumption of Social Responsibilities", Academy of Management Journal, 1, 312322.

Denison, D. R., (1984), "Bringing Corporate Culture to the Bottom Line." Organizational Dynamics, $13,4-22$.

Dewi, S. P., (2012), "Pengaruh Pengendalian Internal dan Gaya Kepemimpinan terhadap Kinerja Karyawan SPBU Yogyakarta (Studi Kasus pada SPBU Anak Cabang Perusahaan RB. Group)", Jurnal Nominal, I (1), 1-22.

Dharma A., (2002), Gaya Kepemimpinan yang Efektif Bagi Manajer, Liandung: CV. Sinar Baru.

Doise, M. L., (2008), An Integration of Corporate Culture and Strategy, The Interrelationships and Impact on Firm Performance. A dissertation University of Arkansas.

Donaldson, G., dan J. Lorsch, (1983), Decision Making at the Top, New York: Basic Books. 
Doney, M., J.P. Cannon, dan M.R. Mullen, (1998), "Understanding the Influence of National Culture on the Development of Trust," Academy of Management Review, Vol. 23 (3), pp. 601-620.

Durendez, A., dan D. Garcia, (2008), "Innovative Culture, Management Control Systems and Performance In Young SMEs", Doctoral Track and Conference, Entrepreneurship Conference, Faculty of Business, University of Cartagena.

Dvir, T., D. Eden, dan M.L. Banjo. (2002), "Self-fulfilling prophecy and gender: Gan women be Pygmalion and Galatea?", Joumal of Applied Psychology, 80, 253-270.

Elenkov, D.S. dan I.M. Maven, (2005), "Top Management Leadership and Influence on Innovation: the Role of Sociocultural Context", Journal of Management, 31(3), 381-402.
Elenkov, S., Detelin, (1997), "Strategic Uncertainty and Environmental Scanning: The Case for Institutional Influences on Scanning Behavior.” Strategic Management Journal, 287-302.

Fama, E., (1980), "Agency Problem and The Theory of The Firm", Journal of Political Ecomomy, 88, 288325 .

Febriyani, A., dan R. Zulfadin, (2003), "Analisis Kinerja Bank Devisa dan bank Non Devisa di Indonesia", Jurnal Kajian Ekonomi dan Keuangan, Vol. (4), Desember 2003. 